\title{
Consórcio de alface e cenoura, com e sem adoção de cobertura morta em Paragominas-PA
}

A forma de cultivo das hortaliças é essencial para o aumento na produtividade, considerando um cenário de maior consumo de alimentos. Diante disso, o estudo objetivou avaliar o consórcio de alface (Lactuca sativa L.) e cenoura (Daucus carota L.), com e sem cobertura morta no município de Paragominas - PA. O experimento foi conduzido no campo experimental da Universidade Federal Rural da Amazônia - UFRA, no município de Paragominas - PA. O delineamento experimental utilizado foi inteiramente casualizado em esquema fatorial $3 \times 2$ com 4 repetições. Os tratamentos foram compostos por três sistemas de cultivo: alface solteira, cenoura solteira e consórcio de alface e cenoura. E duas formas de manejo: com e sem cobertura morta. Para a alface os parâmetros avaliados foram: altura da planta; número de folhas por planta; massa fresca total (MFT); massa fresca da folha (MFF); massa fresca do diâmetro (MFD); massa seca total (MST); massa seca da folha (MSF); massa seca do diâmetro (MSD); área foliar (AF); produtividade e índice morfofisiológico. Para a cenoura avaliou-se o comprimento, diâmetro, peso da raiz, macro e micronutrientes. A avaliação da eficiência do consórcio se deu através do índice de uso eficiente da terra. O sistema solteiro sem cobertura obteve maior índice de infestação de plantas espontâneas e destacou-se com relação aos parâmetros peso e a produtividade. Os índices morfofisiológicos da alface apresentaram efeito significativo na interação entre o cultivo e o manejo. Para a cenoura houve efeito significativo em relação às variáveis peso e produtividade. Na avaliação de macronutrientes e micronutrientes houve destaque para $\mathrm{K}$ e Fe, respectivamente, com as maiores médias de concentração nas raízes. $O$ índice de uso eficiente da terra demonstrou que o consórcio de alface com cenoura foi eficaz no aproveitamento da área de cultivo.

Palavras-chave: Interação; Manejo; Produtividade.

\section{Lettuce and carrot consortium, with and without adoption of dead coverage in Paragominas-PA}

The form of cultivation of vegetables is essential for increasing productivity, considering a scenario of greater food consumption. Therefore, the study aimed to evaluate the consortium of lettuce (Lactuca sativa L.) and carrots (Daucus carota L.), with and without mulch in the municipality of Paragominas - PA. The experiment was conducted in the experimental field of the Federal Rural University of the Amazon - UFRA, in the municipality of Paragominas - PA. The experimental design used was completely randomized in a 3×2 factorial scheme with 4 replications. The treatments consisted of three cultivation systems: single lettuce, single carrot and a mix of lettuce and carrot. And two forms of management: with and without mulch. For lettuce, the parameters evaluated were: plant height; number of leaves per plant; total fresh mass (MFT); fresh leaf mass (MFF); fresh diameter mass (MFD); total dry mass (MST); dry leaf mass (MSF); dry diameter mass (MSD); leaf area (AF); productivity and morphophysiological index. For carrots, length, diameter, root weight, macro and micronutrients were evaluated. The efficiency of the consortium was assessed using the efficient land use index. The single system without cover obtained a higher rate of spontaneous plant infestation and stood out in relation to weight and productivity parameters. The lettuce morphophysiological indices had a significant effect on the interaction between cultivation and management. For the carrot, there was a significant effect in relation to the weight and productivity variables. In the evaluation of macronutrients and micronutrients, $\mathrm{K}$ and Fe stood out, respectively, with the highest root concentration averages. The index of efficient use of the land demonstrated that the consortium of lettuce with carrots was effective in the use of the cultivated area.

Keywords: Interaction; Management; Productivity.

Topic: Proteção de Plantas e Fitotecnia

Received: 06/04/2021

Approved: 03/05/2021

Reviewed anonymously in the process of blind peer.

Antônia Jennifer Lima da Cruz (iD

Universidade Federal Rural da Amazônia, Brasil http://lattes.cnpq.br/3984159379597766

http://orcid.org/0000-0002-2970-1092

jennifer_cruz19@hotmail.com

Nilvaneide Evangelista dos Santos (iD Universidade Federal Rural da Amazônia, Brasil http://lattes.cnpq.br/0878814285842445 http://orcid.org/0000-0003-0075-3179 nil-evangelista@hotmail.com

\section{Andreza Sousa Carmo (iD}

Universidade Federal Rural da Amazônia, Brasil

http://lattes.cnpq.br/8688515180055231

http://orcid.org/0000-0002-2462-9175

sousa.andreza08@gmail.com
Luana Keslley Nascimento Casais (iD

Universidade Federal Rural de Pernambuco, Brasi http://lattes.cnpq.br/8075409193627849 http://orcid.org/0000-0001-7197-5524 luana.casais@gmail.com

Rhaiana Oliveira de Aviz (iD)

Universidade Federal Rural de Pernambuco, Brasil http://lattes.cnpq.br/2715037307668915

http://orcid.org/0000-0002-4462-4339 rhaianaoliveiradeaviz@gmail.com

Pablo Henrique de Almeida Oliveira (iD)

Universidade Federal Rural de Pernambuco, Brasil

http://lattes.cnpq.br/8828941747437701

http://orcid.org/0000-0001-9128-6179

pabloalmeidaagro@gmail.com
Luis de Souza Freitas (iD

Universidade Federal Rural da Amazônia, Brasi http://lattes.cnpq.br/0747504282703764 http://orcid.org/0000-0003-2321-5269 luisufra@gmail.com

Luciana da Silva Borges (iD

Universidade Federal Rural da Amazônia, Brasi http://lattes.cnpq.br/4533722536181534 http://orcid.org/0000-0002-1194-6411 luagro06@yahoo.com.br

\section{Referencing this:}

CRUZ, A. J. L.; SANTOS, N. E.; CARMO, A. S.; CASAIS, L. K. N; AVIZ, R. O.; OLIVEIRA, P. H. A.; FREITAS, L. S.; BORGES, L. S.. Consórcio de alface e cenoura, com e sem adoção de cobertura morta em Paragominas-PA. Revista Ibero Americana de Ciências Ambientais, v.12, n.5, p.58-69, 2021. DOI: http://doi.org/10.6008/CBPC2179-6858.2021.005.0006 


\section{INTRODUÇÃO}

A alface (Lactuca sativa L.) é uma hortaliça pertencente à família Asterácea, uma das hortaliças folhosas mais consumidas no mundo. No Brasil, é o vegetal mais produzido e comercializado sendo bastante utilizada na preparação de salada, devido à facilidade no preparo e por possuir um sabor agradável e refrescante, tem grande importância por ser fonte de sais minerais, de cálcio e de vitaminas (MOREIRA et al., 2014; FERRO et al., 2012; SOUSA et al., 2007). Assim como a alface, a cenoura (Daucus carota L.) é uma hortaliça que possui alto valor nutritivo, principalmente vitamina $A$, mas também fornece sódio, cálcio e potássio (SILVA, 2017). É uma raiz originaria da Europa e Ásia, que pertence à família Apiácea (EMBRAPA, 2016; LANA et al., 2010).

Estas duas hortaliças são de grande demanda na Região Norte, com isso estabelecer a forma de cultivo que aumente a produção e paralelamente haja o aproveitamento da área é essencial, desse modo, a utilização de diversos tipos de cobertura morta apresenta-se como uma alternativa viável proporcionando aumento no desempenho da cultura (GUERRA et al., 2017). A prática de cobertura do solo é recomendada em sistemas orgânicos, pois evita perdas excessivas de água, além de enriquecer o solo com nutrientes após a decomposição do material, permitindo melhor desempenho das culturas (SOUZA et al., 2006).

Dentre as vantagens do uso de cobertura no solo destaca-se a redução na incidência de plantas daninhas, não sendo necessária aplicação de produtos químicos (BORGES et al., 2018). Segundo Brighenti (2010) as plantas daninhas ocasionam bastante interferência nas culturas, principalmente no rendimento e na produtividade. São vários os fatores que contribuem para o controle acentuado da emergência de plantas infestantes sob a utilização da cobertura morta, a oscilação de temperatura do solo é reduzida pela camada de palhada, cujas oscilações são necessárias para a quebra de dormência na semente, ocasionando grande impacto na emergência das mesmas (HIRATA et al., 2014).

Outra forma de manejo que contribui para o controle de daninhas é o consórcio de espécies hortícolas, na qual tem sido uma alternativa utilizada por pequenos produtores (OLIVEIRA et al., 2010; MONTERAZO et al., 2006; BEZERRA NETO et al., 2001), proporcionando melhores condições de exploração do uso da terra e dos recursos ambientais, tais como água, nutrientes e radiação solar, além de reduzir a incidência de pragas e doenças e promover a otimização de práticas agrícolas (TELLES et al., 2016; GLIESSMAN, 2009; REZENDE et al., 2009; TAVEIRA, 2000). A forma com que as culturas se relacionam dentro do sistema influencia na eficiência da consorciação (ALMEIDA et al., 2015).

Considerando um cenário de maior consumo e produção de alimentos, faz-se necessário adotar novas formas de produção, para que haja maior produtividade e melhor aproveitamento das áreas disponíveis para cultivo. Diante disso, o estudo teve como objetivo a avaliação do consórcio de alface (Lactuca sativa L.) e cenoura (Daucus carota L.), com e sem a utilização de cobertura morta no município de Paragominas- PA.

\section{METODOLOGIA}

O estudo foi conduzido no campo experimental da Universidade Federal Rural da Amazônia, no 
município de Paragominas - PA. O solo da área de estudo é predominantemente do tipo Latossolo Amarelo muito argiloso (RODRIGUES et al., 2003). Segundo a classificação de Köppen, o clima da região é do tipo Aw, ou seja, tropical chuvoso com estação seca bem definida, apresentando temperatura média anual de $26,5^{\circ} \mathrm{C}$ e precipitação pluviométrica média anual de $1.802 \mathrm{~mm}$ (RODRIGUES et al., 2002). A Região Norte, geralmente, recebe a mesma quantidade de energia solar durante o ano todo, por esta localizada próxima a linha do equador, essa característica divide a região em apenas duas estações: uma chuvosa, de dezembro a maio e outra de menor precipitação, de junho a novembro. Na região os meses de chuva são denominados como "inverno amazônico" (INMET, 2017). O experimento foi conduzido durante o inverno amazônico, em que houve uma variação de temperatura de 20 a $37^{\circ} \mathrm{C}$, os maiores índices de precipitação pluviométrica e umidade relativa foram observados no mês de fevereiro com cerca de $400 \mathrm{~mm}$ e $90 \%$, respectivamente.

Na tabela 1 estão dispostos os dados sobre as características do solo. Para a implantação do experimento o solo foi revolvido e posteriormente foram levantados quatro canteiros, com auxilio de uma enxada rotativa, com as seguintes dimensões: $1,0 \mathrm{~m}$ de largura; 0,30 $\mathrm{m}$ de altura e 9,0m de comprimento, em cada canteiro foram adicionados $2 \mathrm{~kg}$ de terra preta e $2 \mathrm{~kg}$ de esterco de gado por $\mathrm{m}^{2}$.

Tabela 1: Análise química do solo da área experimental.

\begin{tabular}{|c|c|c|c|c|c|c|c|c|c|c|}
\hline \multirow{3}{*}{$\begin{array}{l}\text { Prof. } \\
\text { (cm) }\end{array}$} & \multirow[t]{2}{*}{$\mathrm{pH}$} & $\mathbf{P}$ & $S$ & $\underline{K}$ & $\mathrm{Ca}$ & $\mathrm{Mg}$ & $\mathrm{H}+\mathrm{Al}$ & CTC & SB & \multirow{2}{*}{$\begin{array}{c}\text { M.O } \\
\left(\mathrm{g} / \mathrm{dm}^{3}\right)\end{array}$} \\
\hline & & & $/ \mathrm{dm}^{3}$ & \multicolumn{6}{|c|}{$\mathrm{mmolc} / \mathrm{dm}^{3}$} & \\
\hline & 4,9 & 32 & 35 & 1,9 & 12 & 6 & 42 & 47,5 & 18,6 & 22 \\
\hline
\end{tabular}

O delineamento experimental utilizado foi inteiramente casualizado, em esquema fatorial $3 \times 2$ com quatro repetições. O primeiro fator utilizado foi constituído por três tratamentos: alface solteiro, cenoura solteiro e consórcio de cenoura com alface e o segundo se deu pelo uso de cobertura morta: com e sem cobertura. As dimensões das parcelas experimentais foram de 1,0 x 1,25m. O espaçamento utilizado para a alface solteiro foi de $0,25 \times 0,25 \mathrm{~m}$, sendo distribuídas três plantas por linha, totalizando 18 plantas por parcelas. Para a cenoura solteiro adotou-se o espaçamento de $0,25 \times 0,10 \mathrm{~m}$, com 8 plantas por linha, em um total de 48 plantas por parcela e no consórcio o espaçamento adotado foi o mesmo da alface e da cenoura intercalados, totalizando 33 plantas por parcela.

A cenoura foi semeada direto no canteiro, utilizou-se a cultivar Brasília, que possui um ciclo de 90 a 100 dias. As mudas da alface Veneranda tipo crespa, foram produzidas em bandejas de polietileno expandido com 128 células, empregando como substrato uma mistura de terra preta e palha de arroz na proporção de 2:1. As mudas foram mantidas em viveiro coberto com sombrite $70 \%$. As bandejas foram dispostas em bancadas de madeira. Aos 15 dias após a semeadura, realizou-se o desbaste da alface, mantendo apenas uma planta por célula. As mudas foram adubadas com 10g de ureia para 1 litro de água a cada três dias, e irrigadas diariamente pela manhã e a tarde.

O transplante das mudas de alface para o canteiro foi realizado após 40 dias da semeadura. Durante o experimento foram feitas irrigações diárias e controle de plantas espontâneas através de capina e monda, após a identificação das plantas daninhas. A adubação de cobertura realizada no canteiro foi com 
$10 \mathrm{~g}$ de ureia, $10 \mathrm{~g}$ de Potássio e $100 \mathrm{ml}$ de Boro por linha numa concentração de $1 \mathrm{~g} / \mathrm{l}$ a cada dez dias. A identificação das plantas espontâneas foi realizada 20 dias após a semeadura, em que foi aderido o método do quadrado 50 x $50 \mathrm{~cm}$ de Blanquet (1979). O quadrado foi lançado ao centro de cada parcela e fez-se a contagem e identificação das plantas espontâneas.

Após a colheita, as plantas de alface foram lavadas para retirada das impurezas do campo e secas sobre papel toalha. Em seguida foram realizadas as seguintes avaliações: altura da planta $(\mathrm{cm})$ determinada com o auxílio de uma régua, a contagem manual do número de folhas de todas as plantas, massa fresca ( $\mathrm{g}$ ) e massa seca (g), utilizando uma balança de precisão para realização das pesagens. Seguidamente, as plantas foram acondicionadas em sacos de papel contendo as identificações de tratamento e dispostas em estufa com circulação forçada de ar a $60^{\circ} \mathrm{C}$ por $48 \mathrm{~h}$. Posteriormente, o material seco foi pesado novamente e o resultado expresso em (g). Procedeu-se a análise de crescimento seguindo metodologia descrita por Benincasa (2003), onde:

Índice de área foliar (IAF): determinado através da razão entre os valores da área foliar total e área de solo ocupada pelas plantas, obtidos em cada amostragem para as diferentes cultivares.

$$
I A F=\frac{A F \text { total }}{A S}
$$

Razão de Área Foliar (RAF): Determinada por meio da razão entre os valores da área foliar total e massa seca total, obtidos em cada amostragem para as diferentes cultivares:

$$
R A F\left(d m^{2} g^{-1}\right)=\frac{A F \text { total }}{M S \text { total }}
$$

Área Foliar Específica (AFE): Este parâmetro foi determinado calculando a razão entre a área foliar e a massa seca das folhas:

$$
A F E\left(d m^{2} g^{-1}\right)=\frac{A F}{M S \text { folhas }}
$$

Razão de Peso das Folhas (RPF): A razão de peso de folhas é calculada pela razão entre a massa seca de folhas e a massa seca total:

$$
R P F\left(g g^{-1}\right)=\frac{M S \text { folha }}{M S \text { total }}
$$

Quantidade de água na parte aérea (QAPA) (g por conjunto de plantas): A quantidade de água na parte aérea foi obtida através da diferença entre a massa de matéria fresca e seca da parte aérea das plantas avaliadas.

$$
Q A P A(g)=M F-M S
$$

Peso específico foliar (PEF) ( $\mathrm{g} \mathrm{cm}^{-2}$ por conjunto de plantas): 0 peso específico foliar foi estimado através da divisão da massa seca da parte aérea pela área foliar.

$$
P E F\left(\mathrm{gcm}^{-2}\right)=\frac{M S}{A F}
$$

Produtividade Econômica: Foi calculada através da massa fresca das folhas pelo número de plantas 
por $\mathrm{m}^{2}$.

$$
P E=\frac{M F \text { folhas }}{n^{\circ} \text { de plantas } / m^{2}}
$$

Para a avaliação dos parâmetros da cenoura, após a colheita as folhas foram removidas e as raízes lavadas para remoção de solo e demais impurezas, em seguida secas sobre papel toalha. Prosseguiu-se com as respectivas avaliações: Comprimento da raiz $(\mathrm{cm})$, usando uma régua métrica, peso $(\mathrm{g})$, avaliação de macro e micronutrientes por meio de amostras de cada parcela secas em estufa $60^{\circ} \mathrm{C}$ por 72 horas e posteriormente enviadas ao laboratório do Instituto Brasileiro de Análises Químicas, Físicas e BiológicasIBRA em São Paulo.

Os dados obtidos foram analisados estatisticamente através da análise de variância, com teste F. Quando houve significância para o fator foi aplicado teste de Tukey (5\%) para a comparação de médias. Todas as análises foram realizadas utilizando-se os recursos computacionais do programa SISVAR (FERREIRA, 2011).

\section{RESULTADOS E DISCUSSÃO}

O quantitativo das principais espécies de plantas espontâneas encontradas em cada cultivo está disposto na tabela 2 em que a maior incidência de plantas daninhas pode ser observado no cultivo solteiro sem cobertura, que apresentou o total de 225 indivíduos, resultado semelhante foi encontrado por Resende et al. (2005) ao testar cultivo da cenoura em diferentes tipos de coberturas, onde todas as coberturas mortas estudadas reduziram significativamente o número total de plantas daninhas em relação ao solo descoberto. A espécie mais encontrada nos tratamentos foi a Cyperus iria conhecido popularmente como tiririca. Melhorança Filho et al. (2008) afirmam que dentre as espécies invasoras na cultura da alface, a tiririca é a de maior destaque.

Tabela 2: Principais espécies de plantas daninhas encontradas no cultivo consorciado e solteiro de alface (Lactuca sativa L.) e cenoura (Daucus carota L.) produzido no município de Paragominas - PA.

\begin{tabular}{|c|c|c|c|}
\hline Cultivo & Tratamentos & Nome científico & $\mathrm{N}^{\circ}$ de indivíduos \\
\hline & \multirow{6}{*}{ Cobertura } & Urochloa decumbens & 15 \\
\hline \multirow[t]{3}{*}{ Consórcio } & & Senna obstusifolia (L.) H.S.Irwin \& Barneby & 29 \\
\hline & & Cyperus iria L. & 169 \\
\hline & & Alternanthera tenella Colla & 29 \\
\hline \multirow[t]{3}{*}{ Solteiro } & & Senna obstusifolia (L.) H.S.Irwin \& Barneby & 21 \\
\hline & & Cyperus iria L. & 149 \\
\hline & \multirow{6}{*}{ Sem cobertura } & Senna occidentalis (L.) & 43 \\
\hline \multirow[t]{3}{*}{ Consórcio } & & Phyllantus tenellus & 28 \\
\hline & & Cyperus iria L. & 125 \\
\hline & & Portulaca oleracea & 29 \\
\hline \multirow[t]{2}{*}{ Solteiro } & & Urochloa decumbens & 38 \\
\hline & & Cyperus iria L. & 158 \\
\hline
\end{tabular}

Para interação cultivo (consórcio e solteiro) e manejo (com e sem cobertura) nas características de peso, MST (massa seca total), AF (área foliar), e produtividade da cultura da alface é possível verificar que houve efeito significativo (tabela 3), demonstrando que ambos os fatores influenciaram nas características 
fitotécnicas da alface. Desta forma foi realizada a análise de desdobramento para verificar qual fator representa estatisticamente melhor o resultado para cada característica.

Em relação aos fatores de peso, MFT e produtividade, verificou-se efeito significativo, em que o cultivo solteiro sem cobertura apresentou os melhores resultados (tabela 3). Sendo essas variáveis diretamente proporcionais. Para Algeri et al. (2018) a maior produtividade observada em monocultivo se dá, possivelmente, pela menor competição interespecífica.

Quanto as variáveis MST e área foliar (AF) também foi observado efeito significativo, onde houve destaque para o cultivo solteiro (tabela 3). De acordo com Zuffo et al. (2016) o reflexo da maior AF em plantas é maior área fotossintética, consequentemente, maior produção de fotoassimilados, resultando em crescimento e desenvolvimento. Casais et al. (2020), ao estudar sistemas de cultivo e propagação na região de Paragominas também obtiveram resultados significativos para o parâmetro área foliar. Aviz et al. (2019) analisando área foliar de alface na mesma região de cultivo desse trabalho e obtiveram resultados que variaram de 87,03 a $123,70 \mathrm{~cm}^{2}$, assim como Pereira Junior et al. (2020), obtiveram valores de área foliar entre $61,52 \mathrm{~cm}^{2}$ a $86,94 \mathrm{~cm}^{2}$ em alface.

Com relação ao número de folhas foi observado efeito significativo no cultivo solteiro. Com relação ao manejo com e sem cobertura, não houve resultado significativo (tabela 3). Resultados semelhantes aos encontrados nesse trabalho também foram observados em estudo realizado por Negreiros et al. (2002) em que houve maior número de folhas de alface por planta no sistema solteiro dentro de cada cultivar estudada. Pereira Junior et al. (2020), obtiveram resultados satisfatórios em número de folhas em alface produzida na região de Paragominas no período chuvoso.

Assim como no número de folhas, na massa fresca total (MFT) o cultivo solteiro apresentou estatisticamente os melhores resultados. O que foi observado também por Almeida et al. (2014) onde o monocultivo da salsa apresentou maior produção de matéria fresca quando comparada com a salsa consorciada com a rúcula. Damasceno et al. (2016) ao encontrar resultados semelhantes para estudo com consorciação entre alface e rabanete atribuiu ao fato de que a distribuição das plantas no cultivo solteiro proporcionou melhores condições para o desenvolvimento da cultura, em função da redução da competição entre plantas.

Para o que se refere à altura, dentre os cultivos, o que mais se destacou foi o solteiro em relação ao consórcio (tabela 3), resultado equivalente também observado por Bezerra Neto et al. (2003) onde cultivo solteiro foi superior à altura das plantas do sistema de cultivo consorciado. No que se refere à massa seca total (MST), com relação ao manejo com e sem cobertura do solo não apresentou resultados significativos (tabela 3). Já relacionado ao tipo de cultivo os melhores resultados foram apresentados no cultivo solteiro. Nespoli et al. (2017) encontraram resultado semelhante, onde a menor produção de matéria seca comercial foi registrada na alface em cultivo consorciado quando comparada com aquela do sistema solteiro. 
Tabela 3: Produção de alface em consórcio com cenoura, com cobertura e sem cobertura do solo no município de Paragominas - Pará.

\begin{tabular}{|c|c|c|c|c|c|c|c|c|}
\hline Cultivo & Manejo & $\begin{array}{l}\text { Peso } \\
\text { (g) }\end{array}$ & $\begin{array}{l}\text { Altura } \\
(\mathrm{cm})\end{array}$ & $\mathbf{N}^{\circ}$ de Folhas & $\begin{array}{l}\text { MFT } \\
\text { (g) }\end{array}$ & $\begin{array}{l}\text { MST } \\
\text { (g) }\end{array}$ & $\begin{array}{l}\text { AF } \\
\left(\mathrm{mm}^{2}\right)\end{array}$ & $\begin{array}{l}\text { Prod. } \\
\text { (kg) }\end{array}$ \\
\hline Solteiro & \multirow{2}{*}{ Cobertura } & $36,76 \mathrm{aB}$ & $16,91 \mathrm{aA}$ & $10,25 a A$ & $36,76 a \mathrm{a}$ & $1,99 a \mathrm{a}$ & $44,92 \mathrm{aA}$ & $0,40 a B$ \\
\hline Consórcio & & $10,27 \mathrm{bB}$ & $11,92 \mathrm{bB}$ & $6,25 \mathrm{bA}$ & $10,04 \mathrm{bA}$ & $1,01 \mathrm{bA}$ & $26,81 \mathrm{bB}$ & $0,12 \mathrm{bA}$ \\
\hline Solteiro & \multirow{2}{*}{ Sem cobertura } & $43,33 a A$ & $18,52 \mathrm{aA}$ & $11,33 a A$ & $43,33 a A$ & $2,48 \mathrm{aA}$ & $43,10 a A$ & $0,46 a A$ \\
\hline Consórcio & & $12,11 \mathrm{bA}$ & $13,76 \mathrm{bA}$ & $6,70 \mathrm{bA}$ & $12,11 \mathrm{bA}$ & $0,94 \mathrm{bA}$ & $31,74 \mathrm{bA}$ & $0,14 \mathrm{bA}$ \\
\hline Cultivo & & $* *$ & $* *$ & $* *$ & $* *$ & $* *$ & $* *$ & $* *$ \\
\hline Manejo & & $* *$ & $* *$ & Ns & $* *$ & ns & ns & $* *$ \\
\hline $\mathrm{C} \times \mathrm{M}$ & & $* *$ & $\mathrm{Ns}$ & $\mathrm{Ns}$ & $* *$ & $* *$ & $* *$ & $* *$ \\
\hline Cv (\%) & & 4,41 & 6,95 & 12,28 & 9,12 & 14,96 & 8,40 & 10,25 \\
\hline
\end{tabular}

Médias seguidas pela mesma letra maiúscula correspondem ao manejo (com e sem cobertura) não diferem entre si, médias seguidas pela mesma letra minúscula corresponde ao cultivo (solteiro e consórcio) não diferem entre si pelo teste de Tukey, a 5\% de probabilidade, ns = não significativo, ** significativo, C x M = Interação Cultivo e manejo, Massa fresca total (MFT), Massa seca total (MST), Área foliar (AF).

Na tabela 4 são apresentados os índices morfofisiológicos da alface, RAF, RPF, AFE, PEF, QAPA e IAF, onde ocorreu efeito significativo na interação entre o cultivo (solteiro e consórcio) e o manejo (com e sem cobertura) nas variáveis. Com isso, foi realizado o desdobramento desses resultados para verificar qual fator estatisticamente obteve o melhor resultado. A razão da área foliar (RAF) apresentou efeito significativo tanto no cultivo como no manejo sendo destacado o cultivo consorciado e manejo com cobertura. Diferindo do resultado de Guerrero et al. (2011) em que não foi observado efeito significativo da razão da área foliar em estudo com rúcula. Para a razão de o peso foliar (RPF) o que apresentou melhor resultado foi o consórcio com cobertura com $34,70 \mathrm{~g}$, sendo que o cultivo solteiro não diferiu em relação ao manejo, apresentando o mesmo valor para ambas as formas de manejo.

A área foliar específica (AFE) apresentou resultados significativos com relação ao cultivo e ao manejo, destacando o consórcio com cobertura. Diferente dos resultados encontrados por Moreira et al. (2011), onde não foi detectado efeito significativo sobre a área foliar específica, em estudo dos caracteres morfofisiológicos e produtivos de cultivares de batata-doce, e Viana (2017) em que a rúcula solteira apresentou as maiores média obtidas. A QAPA e PEF foram as variáveis que apresentaram efeito significativo, com os melhores resultados no cultivo solteiro sem cobertura. Diferente do resultado encontrado por Guerrero et al. (2011) em estudo do efeito da aplicação foliar de silício em rúcula cultivada em dois tipos de solos e por Casais et al. (2018) ao analisar a produção de pimentão, onde o QAPA não apresentou diferença significativa em ambos os estudos.

Para o índice área foliar (IAF) pode-se observar que houve efeito significativo, destacando-se o cultivo consorciado com cobertura. Diferindo assim do estudo de Gonçalves et al. (2005) avaliando a cultura da alface em solo coberto com papel filme de polietileno azul e descoberto no qual não foram verificadas diferenças estatísticas para o IAF ao longo do desenvolvimento da cultura. Lima et al. (2020), obtiveram em alface os valores de índice de área foliar (IAF) de 61,67 e 64,09, resultados diferentes do obtido nesse trabalho.

Tabela 4: Índices morfofisiológicos de crescimento: Razão de área foliar (RAF), razão de peso foliar (RPF), Área foliar especifica (AFE), peso específico da folha (PEF), quantidade de água na parte aérea (QAPA), índice área foliar (IAF) da alface (Lactuca sativa L.) produzida no município de Paragominas - Pará.

\begin{tabular}{llcccccc}
\hline Cultivo & Manejo & RAF & RPF & AFE & PEF & QAPA & IAF \\
\hline Solteiro & Cobertura & $11,13 \mathrm{bA}$ & $0,26 \mathrm{bA}$ & $11,13 \mathrm{bA}$ & $0,09 \mathrm{aB}$ & $34,76 \mathrm{aB}$ & $1,22 \mathrm{bA}$
\end{tabular}




\begin{tabular}{|c|c|c|c|c|c|c|c|}
\hline Consórcio & & $34,70 \mathrm{Aa}$ & $0,79 a A$ & $34,70 a A$ & $0,03 \mathrm{bB}$ & $9,03 \mathrm{bB}$ & $1,80 \mathrm{aA}$ \\
\hline Solteiro & & $6,31 \mathrm{bB}$ & $0,26 \mathrm{bA}$ & $6,31 \mathrm{bB}$ & $0,16 a A$ & $40,85 a A$ & $0,85 a B$ \\
\hline Consórcio & sem cobertura & $13,37 a B$ & $0,44 a B$ & $13,37 a \mathrm{~B}$ & $0,07 b A$ & $11,17 \mathrm{bB}$ & $0,69 \mathrm{bB}$ \\
\hline Cultivo & & $* *$ & $* *$ & $* *$ & $* *$ & $* *$ & $* *$ \\
\hline Manejo & & $* *$ & $* *$ & $* *$ & $* *$ & $* *$ & $* *$ \\
\hline $\mathrm{C} \times \mathrm{M}$ & & $* *$ & $* *$ & $* *$ & ns & $* *$ & $* *$ \\
\hline$\overline{C v(\%)}$ & & 5,29 & 10,26 & 5,29 & 17,95 & 4,52 & 5,51 \\
\hline
\end{tabular}

Médias seguidas pela mesma letra maiúscula correspondem ao manejo (com e sem cobertura) não diferem entre si, médias seguidas pela mesma letra minúscula corresponde ao cultivo (solteiro e consórcio) não diferem entre si pelo teste de Tukey, a 5\% de probabilidade, ns = não significativo, ** significativo, C x M = Interação Cultivo e manejo.

O índice de uso eficiente da terra do cultivo solteiro de alface e cenoura e o consórcio entre as duas hortaliças, com e sem cobertura de solo, encontra-se na tabela 5 onde se verifica que o melhor resultado foi obtido no consórcio sem cobertura, apresentando o valor de 1,25, também observado por Bezerra Neto et al. (2008) e Koefender et al. (2016) em que os índices de uso eficiente da terra (UET) nos diversos sistemas consorciados foram maiores que 1. Custódio et al. (2015) inferiu que quando a UET for maior que 1 o consórcio favorecerá o crescimento e a produção das culturas associadas. Isto indica que nestes sistemas ocorreu um melhor aproveitamento dos recursos ambientais, quando comparado com o do sistema solteiro. Oliveira et al. (2017) estudando o consórcio entre rúcula, alface e cenoura obteve razões de equivalente parcial de terra de 1,96, evidenciando a eficiência produtiva do consórcio em relação à monocultura.

Tabela 5: Índice de uso eficiente da Terra do cultivo consorciado de alface e cenoura em Paragominas - PA.

\begin{tabular}{llll}
\hline Cultivo & UET Alface & UET Cenoura & UET sistema \\
\hline Cobertura & $0,306358^{a}$ & $0,689091 \mathrm{~b}$ & $1,038353 a$ \\
Sem cobertura & $0,31445 \underline{a}$ & $0,936993^{a}$ & $1,251443 a$ \\
\hline CV (\%) & $\mathbf{2 8 , 2 6}$ & $\mathbf{8 , 7 3}$ & $\mathbf{3 , 6 7}$
\end{tabular}
Médias seguidas da mesma letra não diferem estatisticamente entre si pelo teste de Tukey a $5 \%$ de probabilidade.

A tabela 6 mostra as médias de peso, comprimento e produtividade da cenoura e a interação entre o cultivo solteiro e o consórcio, e o manejo com e sem cobertura do solo, nessas variáveis. Havendo destaque para os resultados das variáveis referentes ao peso e a produtividade. Para o peso houve efeito significativo em relação ao cultivo solteiro, em que o variou de acordo com o manejo, com e sem cobertura, apresentando valores de $35,71 \mathrm{~g}$ e o $33,32 \mathrm{~g}$ respectivamente. Na interação do $\mathrm{C} \times \mathrm{M}$, os melhores resultados obtidos foram nos cultivos solteiro com cobertura e o consórcio sem cobertura. A produtividade apresentou-se de forma semelhante, observando-se uma relação proporcional entre ambas as variáveis. Isca (2015) observou que a produtividade é influenciada pelo potencial genético das variedades, e obteve produtividade média de 13,18 t/ha para a variedade Brasília.

No comprimento da raiz apesar dos resultados não serem significativos, o que apresentou o melhor resultado foi o cultivo solteiro com cobertura 15, $97 \mathrm{~cm}$. De acordo com a Embrapa (2004) a cultivar Brasília apresenta altura entre 15 a $20 \mathrm{~cm}$, mostrando que os resultados obtidos se encontram de acordo com o esperado pela cultivar.

Na tabela 7 encontram-se os valores dos macronutrientes presentes nas raízes de cenoura cultivada. Os sistemas de cultivo solteiro e consórcio, com e sem cobertura apresentaram os teores de nutrientes na seguinte ordem decrescente: $\mathrm{K}>\mathrm{N}>\mathrm{P}>\mathrm{Ca}>\mathrm{Mg}>\mathrm{S}$. Souza (2003) encontrou a mesma 
sequência decrescente dos nutrientes. Apenas no cultivo solteiro com cobertura o Ca foi maior que o P. Em estudos realizados por Peixoto (2011), o Ca foi encontrado em maior quantidade que o P. Corroborando com o resultado deste trabalho. $\mathrm{O}$ cultivo solteiro sem cobertura apresentou uma concentração de $\mathrm{N}$ e $\mathrm{P}$ superior ao cultivo solteiro com cobertura. Comparando os sistemas de cultivo, o que obteve um maior acúmulo de $\mathrm{N}$ e $\mathrm{P}$ foi o consórcio com cobertura. Segundo a relação apresentada na tabela 7 os níveis de $\mathrm{P}$ estão adequados à cultura, já os níveis de $\mathrm{N}$ encontram-se abaixo do ideal. Dentre os macronutrientes, o K foi o que apresentou a maior média de concentração com valor máximo de 81,25 g/kg, no tratamento com cobertura. Cecílio Filho et al. (2013) verificaram que o K foi o nutriente acumulado em maior concentração em cenoura.

Tabela 6: Peso, comprimento e produtividade de cenoura (Daucus carota L.) produzidas em consórcio com alface no município de Paragominas - Pará.

\begin{tabular}{llccc}
\hline Cultivo & Manejo & Peso (g) & Comprimento (cm) & Produtividade (kg) \\
\hline Solteiro & Cobertura & $35,71 \mathrm{aA}$ & $15,97 \mathrm{Aa}$ & $0,88 \mathrm{bB}$ \\
Consórcio & & $24,41 \mathrm{bB}$ & $15,33 \mathrm{aA}$ & $1,20 \mathrm{aA}$ \\
Solteiro & Sem cobertura & $33,32 \mathrm{aA}$ & $15,39 \mathrm{aA}$ & $1,12 \mathrm{aA}$ \\
Consórcio & & $31,17 \mathrm{aA}$ & $15,29 \mathrm{aA}$ & $* *$ \\
Cultivo & $* *$ & $\mathrm{Ns}$ & Ns \\
Manejo & & $* *$ & $\mathrm{Ns}$ & $* *$ \\
Cx M & & $* *$ & $\mathbf{7 , 2 0}$ & $\mathbf{5 , 9 9}$ \\
\hline Cv (\%) & & $\mathbf{6 , 0 7}$ &
\end{tabular}

Médias seguidas pela mesma letra maiúscula correspondem ao manejo não diferem entre si, médias seguidas pela mesma letra minúscula corresponde ao cultivo não diferem entre si pelo teste de Tukey, a $5 \%$ de probabilidade, ns $=$ não significativo, $* *$ significativo, $\mathrm{C} \times \mathrm{M}=\mathrm{Interação}$ Cultivo e manejo.

Tabela 7: Análise de macronutrientes na cultura da cenoura produzida em Paragominas - PA.

\begin{tabular}{llllllll}
\hline Cultivo & Manejo & $\mathbf{N}$ & $\mathbf{P}$ & $\mathbf{K}$ & $\mathbf{C a}$ & $\mathbf{M g}$ & $\mathbf{S}$ \\
\cline { 3 - 8 } & & & & $\mathrm{g} / \mathrm{kg}$ & & \\
\hline Solteiro & \multirow{2}{*}{ Com cobertura } & 14,6 & 2,47 & 77,25 & 3 & 1,35 & 1,01 \\
Consórcio & 15,11 & 4,44 & 81,25 & 4 & 1,55 & 0,61 \\
Solteiro & \multirow{3}{*}{ Sem cobertura } & 18,25 & 3,26 & 66,5 & 2,75 & 1,6 & 1,01 \\
Consórcio & 12,47 & 2,92 & 64,75 & 2,5 & 1,39 & 1,31 \\
\hline
\end{tabular}

No que se refere às concentrações de micronutrientes encontrados nas raízes de cenoura cultivadas em Paragominas - PA, o Fe foi o micronutriente encontrado em maior quantidade nas raízes de cenoura (Tabela 8). A quantidade de Mn e Zn está abaixo do esperado para essa tuberosa, já o B encontrase no limite do ideal para a cultura (IBRA, 2017).

Tabela 8: Análise de micronutrientes na cultura da cenoura produzida em Paragominas - PA.

\begin{tabular}{lllllll}
\hline Cultivo & Tratamento & B & Cu & Fe & Mn & Zn \\
\cline { 3 - 6 } & & & $\mathrm{mg} / \mathrm{kg}$ & & \\
\hline Solteiro Consórcio & Com cobertura & 82,24 & 8,5 & 200 & 35 & 20,5 \\
& & 63,51 & 10,5 & 180 & 45 & 25,6 \\
Solteiro Consórcio & Sem cobertura & 50,41 & 9,5 & 135 & 40 & 26,95 \\
& & 89,94 & 11 & 115 & 45 & 32 \\
\hline
\end{tabular}

\section{CONCLUSÃO}

O índice de uso eficiente da terra mostrou que o consórcio de alface com cenoura foi eficaz no aproveitamento da área de cultivo. A forma de cultivo mais eficiente foi o consórcio sem cobertura com o índice de 1,25. 


\section{REFERÊNCIAS}

ALGERI, A.; SATO, A. J.; LUCHESE, A. V.; RIBEIRO, I.; PETERLE, A. C.. Cultivo em consórcio de repolho, alface e cenoura. Brazilian Journal of Development, v.4, n.6, p.34363450,2018

ALMEIDA, A. E. D. S.; BEZERRA NETO, F.; COSTA, L. R.; SILVA, M. L. D.; LIMA, J. S. S. D.; BARROS JÚNIOR, A. P.. Eficiência agronômica do consórcio alface-rúcula fertilizado com florde-seda. Revista Caatinga. v.28, n.3, p.79-85, 2015. DOI: https://doi.org/10.1590/1983-21252015v28n309rc

ALMEIDA, T. D. S.; NETA, A.; NILFA, M.; SANTOS, M. P.; DAMASCENA, J.. Produtividade da salsa em cultivo solteiro e consorciado, sob manejo de base agroecológica no norte de Minas Gerais. Productivity parsley in monocropping and intercropping under management of agroecological base in the north of Minas Gerais. Cadernos de Agroecologia, v.9, n.3, 2014.

AVIZ, R. O.; BORGES, L. S.; SILVA, M. J. S.; CASAIS, L. K. N.; CARMO, A. S.; SOARES, D. S.; SILVA, F. C. G.; CARVALHO, F. S.. Adaptação de cultivares de alface (Lactuca sativa L.) ás condições climáticas do sudeste paraense. In: SANTOS, C. A. Grandes temas em agronomia. Maringá: Uniedusul, 2019.

BENINCASA, M. M. P.. Análise de crescimento de plantas: Noções Básicas. 2 ed. Fundação Nacional de Ensino e Pesquisa, 2003.

BEZERRA NETO, F.; ANDRADE, F. V.; NEGREIROS, M. Z. D.; SANTOS JÚNIOR, J. J. D.. Desempenho agroeconômico do consórcio cenoura $x$ alface lisa em dois sistemas de cultivo em faixa. Horticultura Brasileira, v.21, n.4, p.635-641, 2003. DOI: http://dx.doi.org/10.1590/S0102-05362003000400012

BEZERRA NETO, F.; ANDRADE, F.V.; SANTOS JÚNIOR, J. J.; NEGREIROS, M. Z.. Desempenho da cenoura em cultivo solteiro e consorciado com quatro cultivares de alface em dois sistemas de cultivo em faixas. Horticultura Brasileira, v.19, n.2, 2001.

BEZERRA NETO, F.; GOMES, E. G.. Índices de desempenho de sistemas agrícolas consorciados: uso eficiente da terra, indicadores econômicos e eficiência DEA. In: ENCONTRO NACIONAL DE ENGENHARIA DE PRODUÇÃO. A INTEGRAÇÃO DE CADEIAS PRODUTIVAS COM A ABORDAGEM DA MANUFATURA SUSTENTÁVEL, 28. Anais. Rio de Janeiro, 2008.

BORGES, L. D. S.; BASTOS, C. P.; MONTEIRO, C. J. D. S.; SILVA I. B. D.; SOUSA, V. Q.; LIMA, M. S. S.. Incidência de plantas espontâneas no plantio de rúcula (Eruca sativa) em diferentes coberturas mortas, Paragominas-PA. Cadernos de Agroecologia, v.13, n.1, 2018.

BLANQUET, J.. Fitossociologia: bases para el estúdio de las comunidades vegetales. 3 ed. Madrid: H. Blume, 1979.

BRIGHENTI, A. M.. Manual de Identificação e Manejo de Plantas Daninhas em Cultivos de Cana-de-açúcar. Juiz de fora: Embrapa, 2010.

CASAIS, L. K. N.; BORGES, L. S.; MEDEIROS, M. D. B. C. L.; SOUZA, M. E.; SOARES, D. S.. Índices morfofisiológicos e clorofila de hortelã-pimenta cultivadas sob diferentes sistemas de cultivos. Revista Ibero-Americana de Ciências Ambientais, v.11, n.3, p.304-316, 2020. DOI: https://doi.org/10.6008/CBPC2179-6858.2020.003.0024

CASAIS, L. K. N.; AVIZ, R. O.; SANTOS, N. D. F. A.; SILVA MELO, M. R.; SOUSA, V. Q.; SILVA BORGES, L.; LIMA, A. K. O.; GUERREIRO, A. C.. Índices morfofisiolgicos e produção de pimentão produzido em diferentes substratos a base de resíduos orgânicos em ambiente protegido. Revista Agroecossistemas, v.10, n.1, p.174-190, 2018. DOI: http://dx.doi.org/10.18542/ragros.v10i1.5085

CECÍLIO FILHO, A. B.; PEIXOTO, F. C.. Acúmulo e exportação de nutrientes em cenoura 'forto'. Revista Caatinga, v.26, n.1, p.64-70, 2013.

CUSTÓDIO, A. M.; ALVES, E. M.; PAIM, T. P.; CARNEIRO, H. A.; \& JUNIOR, A. L.. Desempenho agronômico de consórcios entre rabanete e alface no Oeste goiano. Revista verde de agroecologia e desenvolvimento sustentável, v.10, n.5, p.56-60, 2015. DOI: https://doi.org/10.18378/rvads.v10i5.3828

DAMASCENO, A. S. V.; MASSAROTO, J. A.; NASCIMENTO JUNIOR, A. P.; MUNHOZ, E. M.. Avaliação da produção de alface e rabanete em consórcio. Revista de Ciências Agroambientais, v.14, n.1, 2016.

EMBRAPA. Empresa Brasileira de Pesquisa Agropecuária. Manual de segurança e qualidade para a cultura da cenoura. Brasília: Embrapa, 2004.

EMBRAPA. Empresa Brasileira de Pesquisa Agropecuária. Alface: a preferida para saladas. Embrapa, 2016.

FERREIRA, D. F.. SISVAR software: versão 5.1. Lavras: DEX/UFLA, 2011

FERRO, J. J. B.; COSTA-CRUZ, J. M. C.; BARCELOS, I. S. C.. Avaliação parasitológica de alfaces (Lactuca sativa) Fcomercializadas no município de Tangará da Serra, Mato Grosso, Brasil. Revista de Patologia Tropical, v.41, p.47-54, 2012. DOI: https://doi.org/10.5216/rpt.v41i1.17745

GLEISSMAN, S. R.. Agroecologia: processos ecológicos em agricultura sustentável. 4 ed. Porto Alegre: Universidade Federal do Rio Grande do Sul, 2009.

GONÇALVES, A. O.; FAGNANI, M. A.; \& PERES, J. G.. Efeitos da cobertura do solo com filme de polietileno azul no consumo de água da cultura da alface cultivada em estufa. Engenharia Agrícola, v.25, n.3, p.622-631, 2005. DOI: https://doi.org/10.1590/S0100-69162005000300007

GUERRA, A. M. N. M.; FERREIRA, J. B. A.; VIEIRA, T. S.; FRANCO, J. R.. Desempenho agronômico e atividade fotossintética de rabanetes nas condições amazônicas. Revista Brasileira De Agropecuária Sustentável, v.7, n.3, 2017. DOI: https://doi.org/10.21206/rbas.v7i3.428

GUERRERO, A. C.; BORGES, L. C.; FERNANDES, D. M.. Efeito da aplicação foliar de silício em rúcula cultivada em dois tipos de solos. Bioscience Journal, v.27, n.4, p.591-596, 2011. 
HIRATA, A. C. S.; NARITA, N.; RÓS, A. B.. Cobertura morta no manejo de plantas daninhas em cebola. Pesquisa \& Tecnologia, v.11, n.1, 2014.

IBRA. Instituto Brasileiro de Análises Químicas, Físicas e biológicas. Relatório de ensaio - 2017. São Paulo, 2017.

INMET. Instituto Nacional de Meteorologia. Boletim agroclimatológico mensal de janeiro - 2017. Brasília, 2017.

ISAC, N. T.. Avaliação do efeito combinado de diferentes níveis de adubação inorgânica NPK e diferentes variedades na produtividade da cenoura Daucus carota L., nas condições do Vale de Umbelúzi. Universidade Eduardo Mondlane, 2015.

KOEFENDER, J.; SCHOFFEL, A.; MANFIO, C. E.; GOLLE, D. P.; SILVA, A. N.; HORN, R. C.. Consorciação entre alface e cebola em diferentes espaçamentos. Horticultura Brasileira, v.34, n.4, p.580-583, 2016. DOI: http://dx.doi.org/10.1590/s0102$\underline{053620160419}$

LANA, M. M.; TAVARES, S. A.. $\mathbf{5 0}$ Hortaliças: como comprar, conservar e consumir. Brasília: Empresa Brasileira de Pesquisa Agropecuária, Brasília, 2010.

LIMA, M. S. S.; BORGES, L. S.; CASAIS, L. K. N.; REZENDE, B. R.; FERREIRA, R. L. C.; AVIZ, R. O.; PONCE, F. S.; FREITAS, L. S. Índices morfofisiológicos de alface produzidas em diferentes substratos sob ambiente protegido. Revista Ibero Americana de Ciências Ambientais, v.11, n.5, p.531-538, 2020. DOI: http://doi.org/10.6008/CBPC2179. $\underline{6858.2020 .005 .0048}$

MELHORANÇA FILHO, A. L.; PEREIRA, M. R. R.; MARTINS, D.; CASTRO, R. M.; NASCIMENTO, M. S.. Produtividade de alface cv Lucy Brown influenciada por períodos de convivência com plantas infestantes e potencial alelopático da tiririca. Bioscience Journal, v.24, n.3, p.19-23, 2008.

MONTEZANO, E. M.; PEIL, R. M. N.. Sistema de consórcio na produção de hortaliças. Current Agricultural Science and Technology, v.12, n.2, 2006. DOI: https://doi.org/10.18539/cast.v12i2.4502

MOREIRA, J. N.; DE QUEIROGA, R. C. F.; JÚNIOR, A. J. D. L. S.; SANTOS, M. A.. Caracteres morfofisiológicos e produtivos de cultivares de batata-doce, em Mossoró, RN. Revista Verde de Agroecologia e Desenvolvimento Sustentável, v.6, n.1, p.161-167, 2011.

MOREIRA, M.; SANTOS, C.; LUCAS, A.; BIANCHINI, F.; SOUZA, I.; VIÉGAS, P.. Lettuce production according to different sources of organic matter and soil cover. Agricultural Science, v.5, p.99-105, 2014. DOI: http://dx.doi.org/10.4236/as.2014.52013

NEGREIROS, M. Z. D.; BEZERRA NETO, F.; PORTO, V. C.; SANTOS, R. H.. Cultivares de alface em sistemas solteiro e consorciado com cenoura em Mossoró. Horticultura Brasileira, v.20, n.2, p.162-166, 2002. DOI: https://doi.org/10.1590/S0102-05362002000200008

NESPOLI, A.; SEABRA JÚNIOR, S.; DALLACORT, R.; PURQUERIO, L. F.. Consórcio de alface e milho verde sobre cobertura viva e morta em plantio direto. Horticultura Brasileira, v.35, n.3, p.453-457, 2017. DOI: https://doi.org/10.1590/s0102-053620170323

OLIVEIRA, E. Q.; SOUZA, R. J.; CRUZ, M. C. M.; MARQUES, V. B.; FRANÇA, A. C.. Produtividade de alface e rúcula, em sistema consorciado, sob adubação orgânica e mineral. Horticultura Brasileira, v.28, n.1, 2010.

OLIVEIRA, L. A. D. A.; BEZERRA NETO, F.; BARROS JÚNIOR, A. P.; SILVA, M. L. D.; OLIVEIRA, O. F.; LIMA, J. S.. Agroeconomic efficiency of polycultures of arugula-carrot-lettuce fertilized with roostertree at different population density proportions. Revista Brasileira de Engenharia Agrícola e Ambiental, v.21, n.11, p.791-797, 2017. DOI: https://doi.org/10.1590/1807-1929/agriambi.v21n11p791$\underline{797}$

PEIXOTO, F. C.. Crescimento e acúmulo de macronutrientes em cenoura "forto". Dissertação (Mestrado em Ciência do Solo) - Faculdade de Ciências Agrárias e Veterinárias, Jaboticabal, 2011

PEREIRA JUNIOR, A. S.; SOARES, D. S.; ALVES, G. A. R BORGES, L. S.; FREITAS, L. S.; SOUZA, M. E.. Produtividade e análise sensorial de cultivares de alface (Lactuca sativa L.) hidropônica em período chuvoso e seco de Paragominas Pa. In: SANTOS, C. A.. Pesquisa e inovação em horticultura. Maringá: Uniedusul, 2020.

RESENDE, F. V.; SOUZA, L. S. D.; OLIVEIRA, P. S. R. D.; GUALBERTO, R.. Uso de cobertura morta vegetal no controle da umidade e temperatura do solo, na incidência de plantas invasoras e na produção da cenoura em cultivo de verão. Ciência e agrotecnologia, v.29, n.1, p.100-105, 2005. DOI: https://doi.org/10.1590/S1413-70542005000100012

REZENDE, B. L. A.; BARROS JÚNIOR, A. P.; CECÍLIO FILHO, A. B.; PÔRTO, D. R. Q.; MARTINS, M. I. E. G.. Custo de produção e rentabilidade das culturas de alface, rabanete, rúcula e repolho em cultivo solteiro e consorciadas com pimentão. Ciência e agrotecnologia, v.33, n.1, p.305-312, 2009. DOI: https://doi.org/10.1590/S1413-70542009000100042

RODRIGUES, T. E.; SILVA, J. M. L.; GAMA, J. R. N. F.; VALENTE, M. A.; OLIVEIRA JUNIOR, R. C.. Zoneamento Agroecológico do município de Paragominas, Estado do Pará. Embrapa, 2002.

RODRIGUES, T. E.; SILVA, R. D. C.; SILVA, J. M. L.; OLIVEIRA JUNIOR, R. C.; GAMA, J. R. N. F.; VALENTE, M. A.. Caracterização e classificação dos solos do município de Paragominas, Estado do Pará. Embrapa, 2003.

SILVA, J. M. D.. Coleções didáticas de sementes de hortaliças, 2017.

SOUSA, C. S.; BONETTI, A. M.; GOULART FILHO, L. R.; MACHADO, J. R. A.; LONDE, L. N.; BAFFI, M. A.; RAMOS, R. G.; VIEIRA, C. U.; KERR, W. E.. Divergência genética entre genótipos de alface por meio de marcadores AFLP. Bragantia, v.66, n.1, p.11-16, 2007. DOI: http://dx.doi.org/10.1590/S0006-87052007000100002

SOUZA, A. F.; MESQUITA FILHO, M. V.; VIEIRA, J. V.; SOUZA, R. M.; MEIRELES, S. M.. Teores de macronutrientes e produção de matéria seca em cenouras do Grupo Brasília, cultivadas em solos sob cerrado. In: CONGRESSO BRASILEIRO DE OLERICULTURA, 43. Anais. Recife, 2003. 
SOUZA, L. S.; RESENDE, P.. Manual de horticultura orgânica. 2 ed. Viçosa: Aprenda Fácil, 2006.

TAVEIRA, M.C.G.S.. Produtividade da cultura da beterraba em função da consorciação com rúcula em diferentes épocas de semeadura. Jaboticabal: Universidade Estadual Paulista, 2000.

TELLES, C. C.; MENDONÇA FUKUSHI, Y. K. K.; BASTOS, P. R. R. P.; ALMEIDA, L. P. L.; JUNQUEIRA, A. M. R.. Cultivo de alface em consórcio com hortaliças tradicionais. Cadernos de Agroecologia, v.10, n.3, 2016.
VIANA, C. D. S.. Eficiência agroeconômica e aspectos fisiológicos no consórcio de rúcula (Eruca sativa Miller) com espécies condimentares. Dissertação (Mestrado em Agronomia/Fitotecnia)-Centro de Ciências Agrárias, Universidade Federal do Ceará, Fortaleza, 2017.

ZUFFO, A. M.; ZUFFO JÚNIOR, J. M.; SILVA, L. M. A. D.; SILVA, R. L. D.; MENEZES, K. O. D.. Análise de crescimento em cultivares de alface nas condições do sul do Piauí. Revista Ceres, v.63, n.2. p.145-153, 2016. DOI: https://doi.org/10.1590/0034-737X201663020005

A CBPC - Companhia Brasileira de Produção Científica (CNPJ: 11.221.422/0001-03) detém os direitos materiais desta publicação. Os direitos referem-se à publicação do trabalho em qualquer parte do mundo, incluindo os direitos às renovações, expansões e disseminações da contribuição, bem como outros direitos subsidiários. Todos os trabalhos publicados eletronicamente poderão posteriormente ser publicados em coletâneas impressas sob coordenação da Sustenere Publishing, da Companhia Brasileira de Produção Científica e seus parceiros autorizados. Os (as) autores (as) preservam os direitos autorais, mas não têm permissão para a publicação da contribuição em outro meio, impresso ou digital, em português ou em tradução. 